\title{
O QUE HÁ DE NOVO NA REVISTA CONTEXTO \& SAÚDE?
}

\author{
WHAT'S NEW IN THE CONTEXTO \& SAÚDE JOURNAL?
}

\begin{abstract}
Thiago Gomes Heck ${ }^{1}$, Giovano Pereira Buratti ${ }^{2}$, Adriane Cristina Bernat Kolankiewicz ${ }^{3}$
${ }^{1}$ Grupo de Pesquisa em Fisiologia (GPeF), Departamento de Ciências da Vida (DCVida), Programa de Pós-Graduação em Atenção Integral à Saúde (PPGAIS), Universidade Regional do Noroeste do Estado do Rio Grande do Sul (Unijuí)

${ }^{2}$ Departamento de Ciências da Vida (DCVida), Programa de Pós-Graduação em Atenção Integral à Saúde (PPGAIS), Universidade Regional do Noroeste do Estado do Rio Grande do Sul (Unijuí)

${ }^{3}$ Grupo de Pesquisa Atenção à Saúde (GPas), Departamento de Ciências da Vida (DCVida), Programa de Pós-Graduação em Atenção Integral à Saúde (PPGAIS), Universidade Regional do Noroeste do Estado do Rio Grande do Sul (Unijuí)
\end{abstract}

Autores correspondentes: Thiago Gomes Heck. email: thiago@unijui.edu.br

Adriane Cristina Bernat Kolankiewicz. email: adriane.bernat@unijui.edu.br

Giovano Pereira Buratti. Email: giovano.buratti@unijui.edu.br

\section{EDITORES}

Thiago Gomes Heck

(Unijuí-Brasil)

Adriane Cristina Bernat Kolankiewicz

(Unijuí-Brasil)

\section{EDITORES DE ÁREA}

Educação \& Saúde

Eva Teresinha de Oliveira Boff

(Unijuí-Brasil)

Fisioterapia \& Saúde

Eliane Roseli Winkelmann

(Unijuí-Brasil)

Ciências Farmacêuticas \& Saúde

Marilei Uecker Pletsch

(Unijuí-Brasil)

Nutrição \& Saúde

Lígia Beatriz Bento Franz

(Unijuí-Brasil)

Nadia Oliveira

(Unipampa-Brasil)

Ingrid Perry

(Unesc-Brasil)

Enfermagem e suas contribuições para a prática

Adriane Cristina Kolankiewicz

(Unijuí-Brasil)

Crhis de Brum

(UFFS-Brasil)

Neila de Souza

(UFSM-Brasil)

Exercício Físico \& Saúde

Thiago Gomes Heck

(Unijuí-Brasil)

Anderson Zampier Ulbrich

(UFPR)

Editora Unijuí

Universidade Regional do Noroeste do

Estado do Rio Grande do Sul (Unijuí)

\section{Editorial}

Agora, no final de 2016, temos a satisfação de publicar mais uma edição da Revista Contexto \& Saúde (RCS). Nesta data divulgamos também alguns dados sobre o processo editorial realizado nos últimos quatro anos, ou seja, dados referentes aos últimos seis números da revista. Nesta trajetória passamos por mudanças em busca de qualificação de nosso processo editorial, ampliando o número de editores, nomeando editores por área (seções da revista) e ampliando o número de seções por edição.

Neste cenário, ampliamos o diálogo e a circulação da RCS entre autores, avaliadores e editores externos à Universidade Regional do Noroeste do Estado do Rio Grande do Sul (Unijuí), instituição responsável pela publicação desta revista. Esse passo foi dado simultaneamente com o processo de inserção dos professores do Programa de Pós-Graduação em Atenção Integral à Saúde (PPGAIS) como editores de área da RCS. Assim, a RCS, em expansão, mantém como premissa a publicação de trabalhos nos mais diferentes modelos e nas mais diversas "subáreas" da saúde, tornando possível a disponibilização de conteúdos para o aprofundamento em temas de interesse que fortalecem o conhecimento disciplinar, necessário para o fomento das relações interdisciplinares.

Esse conjunto de ações permitiu recebermos uma maior diversidade de trabalhos e aperfeiçoar a editoração, e, desta forma, ampliar a visibilidade da revista. Em 2014, 2015 e 2016 recebemos 58, 74 e 114 manuscritos para avaliação respectivamente. Este aumento crescente na procura pela RCS permitiu o aumento do número de trabalhos publicados por edição: de 6 trabalhos publicados no primeiro número de 2014 para 18 trabalhos em cada uma das edições de 2016 (Linha azul na Figura 1). 


\section{Revista}

\section{Contexto}

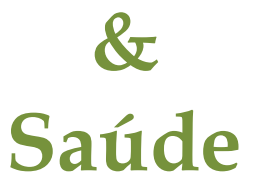

Volume 16

Número 31

2016

ISSN 2176-7114
Destacamos que esse aumento não é acompanhado por maior "flexibilidade" do corpo editorial para atingir um alto número de publicações; ao contrário, em 2014 e 2015 foram rejeitados $19 \%$ e $33 \%$ dos trabalhos submetidos respectivamente, e no ano de 2016 o índice de rejeição chegou a 56\% dos trabalhos.

O esforço do corpo editorial e dos avaliadores ao longo deste período permitiu uma redução importante no tempo entre a submissão do trabalho e a publicação do mesmo. O tempo médio de espera dos autores, que ultrapassava um ano, foi reduzido para aproximadamente nove meses (Linha lilás na Figura 1) e temos a convicção de que este período será ainda mais reduzido nas próximas edições.

Figura 1 - Dados do processo de Editoração da Revista Contexto \& Saúde

A Revista Contexto \& Saúde é um periódico do Departamento de Ciências da Vida da Universidade Regional do Noroeste do Estado do Rio Grande do Sul (Unijuí). É um periódico semestral que tem por objetivo a divulgação da produção técnico-científica de temas relacionados à área de Ciências da Saúde.

O escopo da revista abrange a divulgação de resultados de pesquisa que contemplem avanços no processo saúde-doençacuidado e no conhecimento e aplicabilidade de novos processos químicos e biológicos em saúde.

Neste periódico, entende-se que a publicação de estudos com os aspectos epidemiológicos, assistenciais e educacionais em saúde, experimentais e aplicados é uma forma a subsidiar e qualificar a atenção à saúde de modo interdisciplinar.

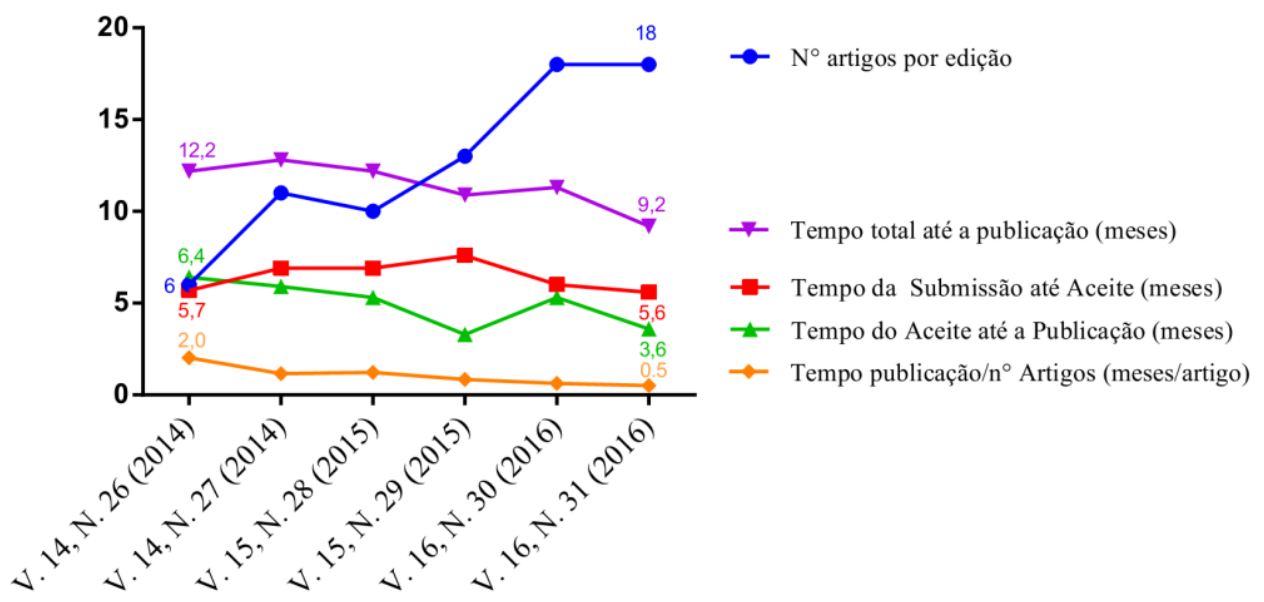

Embora o tempo entre a submissão e a resposta definitiva de aceite para publicação permaneça praticamente inalterado, sendo em torno de cinco meses (Linha vermelha na Figura 1), mantivemos esta latência mesmo com um número aproximadamente duas vezes maior de trabalhos submetidos, comparativamente entre 2014 e 2016. Ainda são necessários avanços nesta etapa crucial: o retorno aos autores com a primeira tomada de decisão editorial. A agilidade neste processo depende do compromisso assumido pelos editores, mas depende fundamentalmente do compromisso dos avaliadores em fundamentar a decisão do corpo editorial em um período menor que três meses - meta da RCS. 
Após as tomadas de decisão editorial, o processo de editoração junto a Editora Unijuí, em uma articulação e diálogo constante entre os editores e funcionários da Editora, é uma etapa que tem contribuído para a qualificação da revista. O tempo de editoração (tempo entre o aceite e a publicação do trabalho, linha verde na Figura 1) foi reduzido praticamente pela metade, chegando, em 2016, a aproximadamente três meses. No conjunto, a "eficiência" editorial pode ser mensurada pela razão entre o tempo de publicação e o número de artigos publicados por número da RCS. Esta fórmula nos permite considerar que levávamos cerca de dois meses de trabalho editorial por artigo publicado, e que, agora, esse tempo pode ser considerado de meio mês de trabalho da equipe por trabalho publicado (Linha laranja na figura 1).

Além de todos os dados que consideramos positivos referentes à RCS, temos a satisfação de informar que já, a partir desta edição, todos os trabalhos da revista passam a ser registrado eletronicamente no Digital Object Identifier System (DOI). Consideramos isto como positivo o contexto da RCS ao longo desses últimos três anos de publicação e promissor para 2017. Agradecemos a todos os autores que escolheram a RCS como periódico para publicação de seus artigos, os revisores que contribuíram para a avaliação mais rigorosa dos textos, os editores que se empenharam na busca de avaliadores e na avaliação dos trabalhos, e todos os funcionários que têm buscado um processo editorial cada vez mais eficiente. 